\title{
Factors affecting the potential for fibre contamination in purpose-designed forensic search rooms
}

\author{
C ROUX*, J HUTTUNEN, K RAMPLING \\ Department of Chemistry, Materials and Forensic Science, University of Technology, Sydney, PO Box 123, Broadway \\ NSW 2007, Australia \\ and \\ J ROBERTSON
}

Forensic Services, Australian Federal Police, GPO Box 401, Canberra ACT 2601, Australia

Science \& Justice 2001; 41: 135-144

Received 26 February 2001; accepted 24 April 2001

This study investigated fibre movement within and out of a search room, when performing a garment examination. The effect of the collection procedure (taping $v$. scraping) on the number of contaminant fibres produced, and the effectiveness of a number of cleaning techniques and varying degrees of examiner hygiene were also studied. Fibre movement was found to be dependent upon distance, with fibre populations decreasing with increasing distance from the garment examination area. Most fibres were deposited during the actual examination. Cotton fibres were more easily shed and also found to be airborne for longer periods of time than wool, acrylic and polyester fibres. The 'scraping method' of fibre recovery was found to result in an increase in the number of loose fibres with transfer to the examiner's clothing and a number of fibres exiting the search room. It is unlikely that a completely clean search room can be obtained. However, with proper precautions it is possible to minimise and monitor the contaminant fibre population. These features are presented and discussed in this paper.

Cette étude évalue le mouvement de fibres à l'intérieur et hors d'un laboratoire de recherches de traces lorsqu'un vêtement est examiné. L'effet du processus de collection (adhésif contre peignage) sur le nombre de fibres de contamination produites et l'efficacité de diverses techniques de nettoyage et les différents degrés d'hygiène de l'examinateur ont également été étudiés. Le mouvement de fibres est dépendant de la distance avec les populations de fibres qui décroissent lorsque la zone d'examen de l'habit est à une distance plus éloignée. La plupart des fibres ont été déposées pendant l'examen luimême. Les fibres de coton ont été perdues plus facilement et également retrouvées dans l'air pour des périodes de temps beaucoup plus longues que la laine et les fibres acryliques et polyesters. La méthode par peignage pour récolter des fibres produit une augmentation du nombre de fibres libres avec transfert sur l'habit de l'examinateur et un certain nombre de fibres sortant de la zone de recherche. Il est improbable qu'une salle de recherches complètement propre puisse être obtenue. Cependant avec des précautions adéquates, il est possible de minimiser et de déterminer la population de fibres contaminantes. Ces éléments sont présentés et discutés dans cet article.

C) The Forensic Science Society 2001

* Corresponding author, Fax: +61 2 95141460, Email: claude.roux@uts.edu.au

Key Words: Forensic science, criminalistics, fibres, contamination, recovery, protocols, taping, scraping, search rooms.
Es wurde während der Spurensicherung an einem Bekleidungsstück die Faserverschleppung innerhalb eines Spurensicherungsraums und aus diesem heraus untersucht. Die Auswirkung der Spurensicherungsmethode (Klebeband versus Scraping) auf die Anzahl der entstehenden flottanten Fasern, die Effektivität einer Reihe von Säuberungstechniken sowie unterschiedliche Hygienegrade des Spurensicherers wurden ebenfalls untersucht. Mit zunehmender Entfernung vom Ort der Sicherung verringerte sich die Anzahl der flottanten Fasern. Die größte Anzahl solcher Fasern erzeugte der Sicherungsvorgang. Baumwollfasern wurden besser abgegeben und hielten sich länger in der Luft als Woll-, Acrylund Polyesterfasern. Durch die Scraping-Methode entstanden mehr flottante Fasern, die sich nicht nur auf die Bekleidung des Sichernden übertrugen sondern sich auch im Raum ausbreiteten. Es ist unwahrscheinlich einen vollständig reinen Spurensicherungsraum zu schaffen. Mit geeigneten Vorkehrungen ist es jedoch möglich, die Anzahl flottanter Fasern zu minimieren und die kontaminierende Faserpopulation aufzuzeichnen.

Este estudio investigó el movimiento de las fibras dentro y fuera de la habitación de búsqueda cuando se realiza una investigación de ropas. Se estudió también el efecto del procedimiento utilizado (golpeo versus rascado) sobre el número de fibras producidas, la eficacia de una serie de técnicas de limpieza y diversos grados de higiene del examinador. Se encontró que el movimiento de las fibras era dependiente de la distancia, decreciendo la población de fibras al aumentar la distancia al área de examen de la ropa. Muchas de las fibras se depositaban durante el examen en curso. Las fibras de algodón se pelaban con más facilidad y se mantenían en el aire durante más tiempo que las de lana, acrílicas o de poliéster. Se encontró que el método de rascado para la obtención de las fibras producía un aumento en el número de fibras sueltas que se transferían a la ropa del examinador y que salían de la habitación de búsqueda. Es improbable que se pueda tener una habitación de búsqueda totalmente limpia. Sin embargo, con ciertas precauciones, es posible minimizar y monitorizar la población de fibras contaminantes. Estos rasgos se presentan y discuten en este trabajo. 


\section{Introduction}

Fibres provide valuable evidence in a variety of categories of investigation and can still assume vital importance in some instances [1]. Their use, analysis and value have been widely investigated and documented for the last twenty years [2-6].

In the laboratory, the first step of forensic fibre examination involves searching and collecting extraneous fibres on the surface of exhibits, often garments. Best forensic practice involves the use of search rooms, which are set aside specifically for this purpose. This is to minimise the potential for contamination from sources that exist in the general laboratory environment due to the nature of garments and their ability to shed fibres easily.

In general, contamination can fall into two categories. The first type of contamination is that confined to a particular case, where fibres from one evidential item are transferred to another item following collection by a police officer or a crime scene examiner. It may be caused by a primary transfer (e.g. two garments are packaged or transported together), or by a secondary or higher degree transfer. Secondary contamination may result from two garments being examined in the same search room, without proper cleaning between examinations, or by the examiners passing fibres from one garment to the other via their clothing or hands. The second type of contamination is known as environmental contamination and is caused by garments being placed in the same environment where they both collect fibres originating from that environment. For example, two garments exposed to the same environment within a laboratory may result in the transfer of background fibres to each of the items.

The implications of fibre contamination during forensic casework are very serious as it may result in what is known as a false positive, leading to a wrongful accusation, arrest and subsequent conviction. A recent example of such a miscarriage is that of the conviction, and later exoneration, of Guy Paul Morin in Canada, in 1992. Morin was convicted for the murder of Christine Jessop with fibre evidence being a major part of the prosecution's case. An inquiry into the case was held in 1996, following Morin's acquittal in 1995, and found a number of crucial errors, including contamination of the evidence whilst at the laboratory. The items were believed to have been contaminated by a person handling the evidence whilst wearing a red sweater without a laboratory coat or other protective clothing. The findings of the inquiry, by Kaufman [7], called for more stringent procedures to reduce the possibility of contamination, as well as research into the development of more universal best practices regarding fibre examinations.

Despite the paramount importance of the contamination issue, only one study has been published into the possibility of contamination occurring during fibre searches within the laboratory. Moore and co-workers [8] found that significant airborne material was not only produced, but also capable of moving small distances (about $1.2 \mathrm{~m}$ ) between benches. Small amounts could even be found several days after the completion of the examination itself. However, their most significant finding was that fibres were not transferred between adjacent rooms. This would make the use of separate rooms for "known" and "unknown" samples worthwhile in preventing contamination.

The paucity of research in this area prompted the present study that investigated fibre movement, both within and out of forensic search rooms. The effect of the collection procedure on the number of contaminant fibres produced, and the effectiveness of a number of cleaning techniques and varying degrees of examiner hygiene, were also studied.

\section{Materials and Methods}

This study involved experiments whereby loose fibres were generated and transferred into the environment via mock garment examinations. These fibres were systematically sampled and counted, and the results were analysed with respect to the following parameters: distance; time; fibre type; collection and cleaning; and protective procedures.

\section{Garments}

Four garments were used in these experiments (Table 1). Garment A was used for two separate series of experiments conducted two years apart in order to test the repeatability of the trends observed.

TABLE 1 The four garments used in this study.

\begin{tabular}{llllll}
\hline Garment & Fibre Type & Colour & Brand & \multicolumn{1}{c}{ Appearance } & Garment Shed \\
\hline A & Cotton & Orange & Espirit & Ribbed knit long-sleeved sweater & High \\
B & Acrylic & Purple & St James & Short-sleeved knit sweater & Medium \\
C & Wool & Maroon & St James & Sleeveless knitted vest & High \\
D & Polyester & Red & Miss Shop & Smooth and shiny knee-length skirt & Low
\end{tabular}

NB: Garment sheddability was assessed by counting the number of fibres collected by a $7.5 \mathrm{~cm}$ length of tape after only one pressing, using Coxon et al. [9] for guidance. 


\section{Search room preparation}

A total of four search rooms were used; two from one forensic laboratory and two from another. In all but experiment 4 , the rooms were cleaned using a non-shedding cloth and $70 \%$ ethanol in water to wipe the main examination table and side benches and then mopping the floor using water and a sponge mop. During the cleaning the examiner wore a $100 \%$ polypropylene protective suit. A piece of brown paper was placed and taped to the examination table to cover the working area (approximately half of the table). A piece of white butcher's paper was then placed on the top of the brown paper and gently wiped with a non-shedding cloth moistened with a $70 \%$ ethanol solution.

\section{Mock examination}

Garments were subjected to mock examinations following two different standard procedures: taping and scraping.

For the taping method, the garment was laid out on the work-area, front upward, and searched with gloved hands using tweezers and a magnifying lens for seven minutes. The garment was then turned over and searched in the same manner for a further seven minutes. For the following seven minutes, three pieces of adhesive tape were used to tape-lift the back of the garment and a further three pieces were then used to tape-lift the front. The garment was then gently shaken over the work-area for four minutes.

In the scraping technique, after the initial search using tweezers, the garment was hung using a vertical adjustable metal frame and scraped with a metal spatula on the frontside for two minutes and then on the back-side for an additional two minutes. During this process the top of the garment was approximately at $110 \mathrm{~cm}$ above the table surface. This technique was applied at the end of the study and only with garments $\mathrm{A}$ and $\mathrm{B}$.

\section{Sampling}

Throughout this study, contaminant fibres present at selected locations were collected using both active and passive sampling. Active sampling involved the use of $15 \mathrm{~cm}$ lengths of $2.5 \mathrm{~cm}$ wide clear adhesive tape. Whilst holding with both gloved hands, the tape was placed onto the area to be sampled and pressed down with a finger. It was then lifted and the area was "scanned", the procedure being repeated fifteen times for each piece of tape. The tape was then placed onto a piece of A4 transparent acetate backing sheet, which was then labelled with relevant information. Passive sampling involved pieces of $15 \mathrm{~cm} \times 15 \mathrm{~cm}$ clear self-adhesive book cover. These were placed, adhesive side up, in the area to be sampled and held down by placing two microscope slides on opposite edges. Following exposure for a set period of time, the adhesive was collected by placing a piece of A4 acetate over the contact and then taping the edges to prevent contamination. The sheets were also labelled with the relevant information.

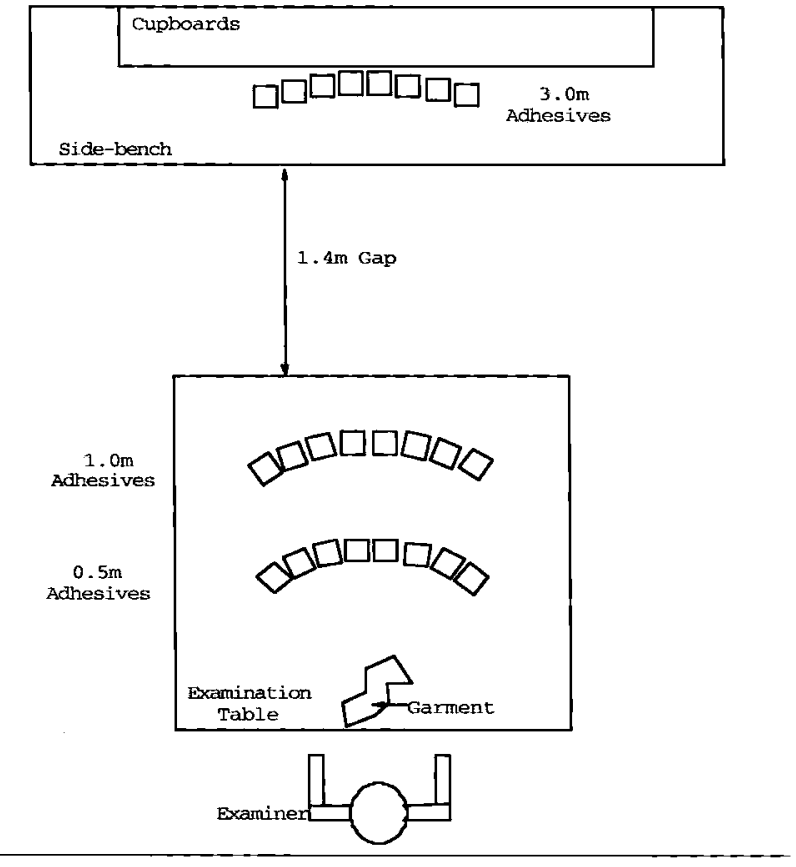

FIGURE 1 Setup used for Experiment 1. Eight adhesives were placed out at three distances at the beginning of the experiment, and then collected at certain times after completion of the examination.

Both types of samples were searched for the relevant target fibres using a Leica MS5 low-power stereomicroscope $(\times 16$ to $\times 40)$ as well as a Maxcan Micro Imager automatic fibre finder. Results obtained by the latter were manually checked for accuracy.

\section{Experiment 1: Fibre movement and distance within the search room}

This experiment was designed to find out how fibres move with respect to both time and distance. The set-up involved three sets of up to eight upturned pieces of tape: at half-ametre, one metre and three metres from where the mock garment examination was conducted (Figure 1). During the examination, the adhesives collected fibres shed from the garment. Then immediately after the examination, one adhesive from each of the three sets was collected. Another one was collected 15 minutes later, and the rest were collected at set times over the next 48 hours. No activity occurred in the room during this period.

Pieces of tape were also located at several locations (e.g. doorway, store room) around the room for the duration of an examination in order to investigate the movement of fibres over short distances.

Experiment 2: Fibre movement and time within the search room

Experiment 1 was modified slightly in order to give a clearer picture of what was happening with respect to time. Only one adhesive was located at each of the three distances 


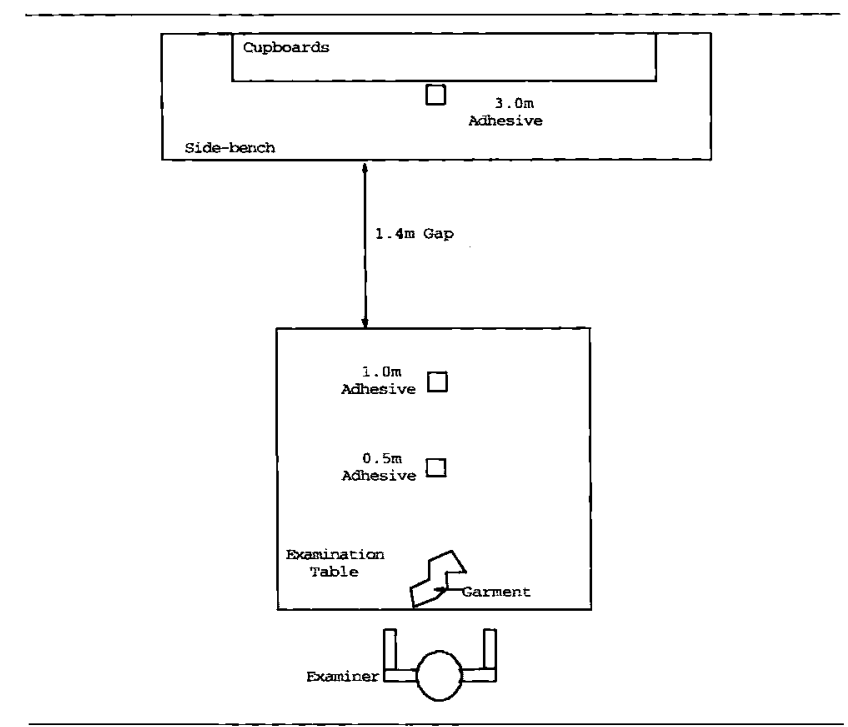

FIGURE 2 Setup used for Experiment 2. Only one adhesive was placed at each of the three distances at the beginning of the experiment, and they were replaced at set times.

during the examination (Figure 2). At the end of the examination, these three pieces of adhesive were removed and replaced with another set. This was repeated at set times over the following two days during which there was no other activity in the Search Room.

\section{Experiment 3: Fibre movement out of the search room}

As there were a number of examinations conducted using Garment A in one of the two forensic laboratories, several adhesives were placed on the floor in different rooms and corridors adjacent to the search room, at a distance of $3 \mathrm{~m}$ to $53 \mathrm{~m}$ from the actual examination bench (Figure 3). Garment A was not exposed in any of these rooms and corridors at any time. However, the activity in these rooms was normal and no precautions were taken to stop contamination by the target fibres. The collections were stopped after four weeks.

\section{Experiment 4: Hygiene in the search room}

This experiment sought to examine hygiene and cleaning practices in the search room. To observe the effectiveness of common precautionary steps, simulations were performed exhibiting different degrees of precaution against contamination by material leftover from previous examinations. Mock examinations were performed on separate days, with at least one day in between each experiment with Garment A. Cleaning procedures involved mopping or sweeping the floor, and wiping the examination table with a dry paper cloth, a paper cloth moistened with a $70 \%$ ethanol solution, a dry non-shedding cloth and a non-shedding cloth moistened with a $70 \%$ ethanol solution. The effectiveness of the protective garment was also tested by tape-lifting single-use polypropylene protective suits and ordinary laboratory coats (cotton:polyester, 50:50) before and after the examination.

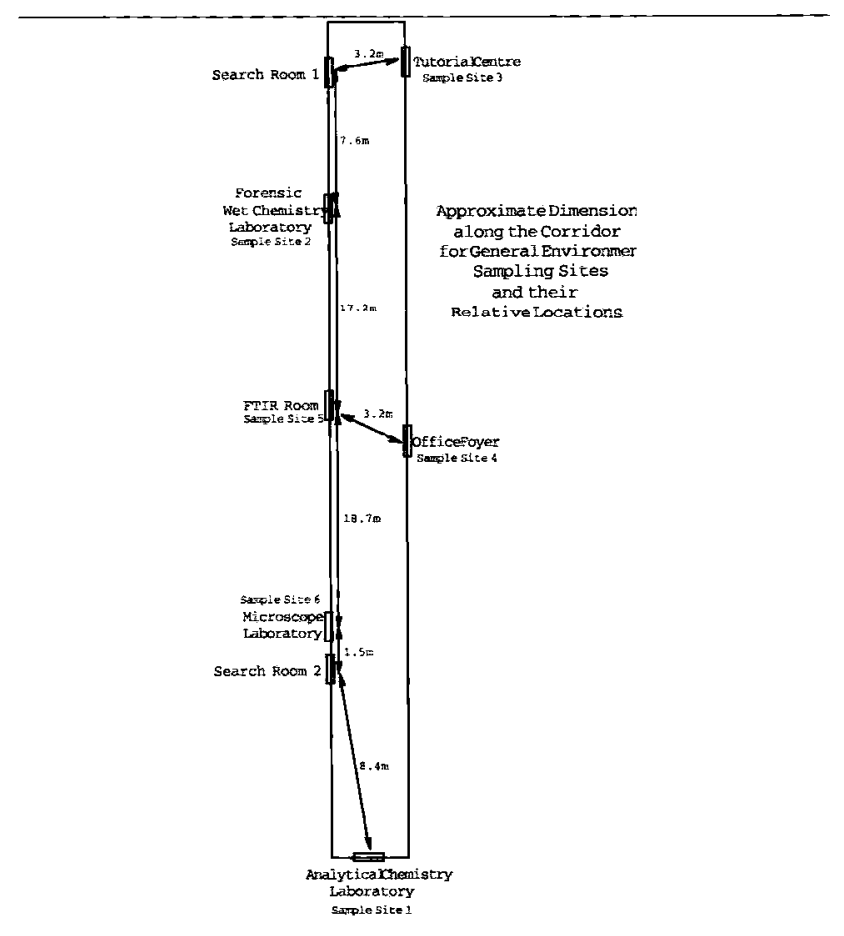

FIGURE 3 The relative locations of the other rooms that were sampled (Experiment 3)

\section{Results}

In order to limit the amount of data, and for consistency purposes, the results presented below are those obtained using the search rooms located at the University of Technology, Sydney. The data acquired at the Australian Federal Police, Canberra, led to similar observations.

\section{Experiment 1: Fibre movement and distance within the search room}

All garments examined showed a similar trend concerning fibre movement with distance: more fibres were deposited at shorter distances (Figures 4-9). The actual number of fibres produced was variable and depended upon the sheddability of the garment. There was no increasing trend for the fibre count with time, i.e. most fibres were deposited at or shortly after garment examination. The apparent sinusoidal pattern was identified as an artefact due to the air ventilation system, and could be considered as noise.

These general trends were not affected by the collection method (taping v. scraping) applied. However, the scraping method produced between two and six times more target fibres than taping. Also, scraping generated increased numbers of target fibres at all three distances.

Small numbers of fibres were found on adhesives left in the space under the door between the doorway and the search room after the examination of any garment using the taping method ( 0 to 6 fibres maximum). In contrast, 25 to 63 fibres were found on adhesives located at the same locations with the scraping method applied to Garment $A$. The scraping of 


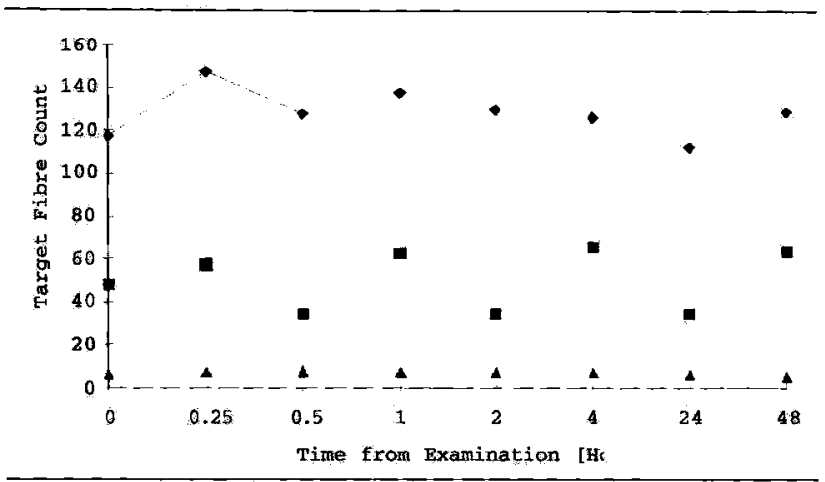

FIGURE 4 Number of fibres found on a $15 \mathrm{~cm} \times 15 \mathrm{~cm}$ area after the examination of Garment $A$ (taping). Experiment 1 $0.5 \mathrm{~m}: \longrightarrow-1 \mathrm{m:} \rightarrow-3 \mathrm{~m}:-\Lambda-$

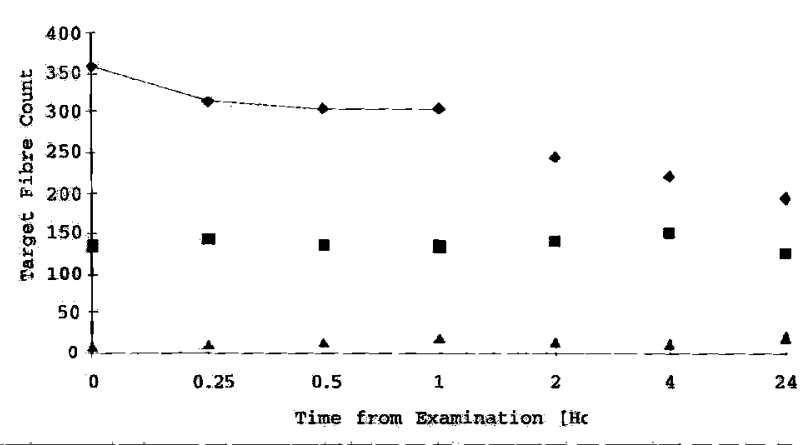

FIGURE 5 Number of fibres found on $a 15 \mathrm{~cm} \times 15 \mathrm{~cm}$ area after the examination of Garment $A$ (scraping). Experiment 1 $0.5 \mathrm{~m}: \rightarrow-1 \mathrm{~m}: \rightarrow-3 \mathrm{m:}-\Delta-$

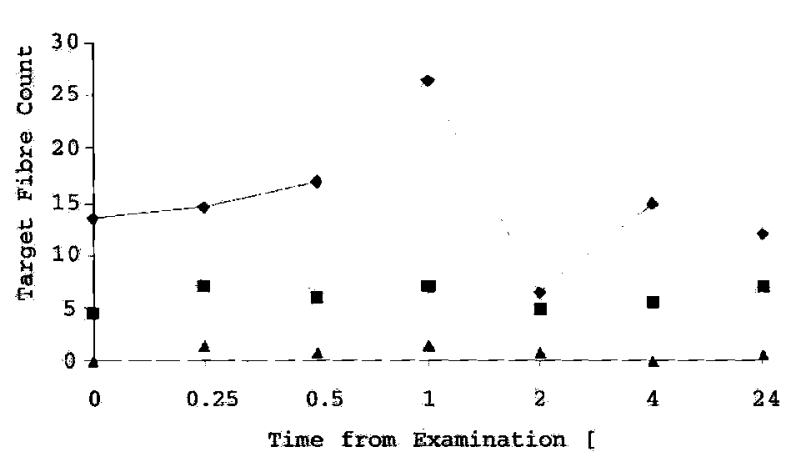

FIGURE 6 Number of fibres found on a $15 \mathrm{~cm} \times 15 \mathrm{~cm}$ area after the examination of Garment $B$ (taping). Experiment 1 $0.5 \mathrm{~m}:-1 \mathrm{~m}:-1-3 \mathrm{~m}:-\Delta-$

Garment B, however, was not found to increase the number of targets being present under the doorway in comparison to taping.

Experiment 2: Fibre movement and time within the search room

During the examination fibres were deposited at all three distances, in a fashion similar to what was observed in Experiment 1, with more fibres at shorter distances (Figures 10-15). After the examination there were very few fibres, if any, deposited at all three locations when using the taping

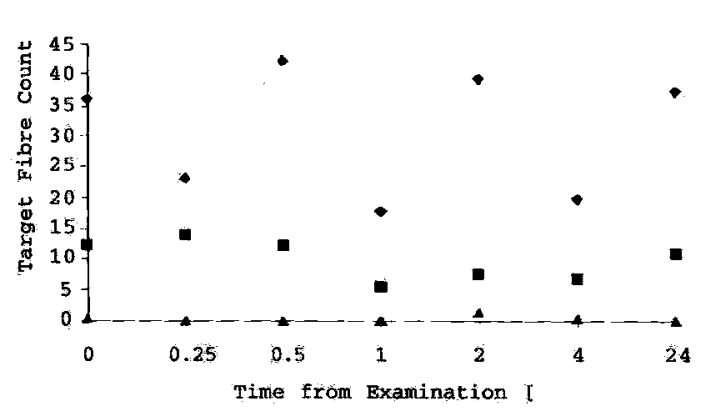

FIGURE 7 Number of fibres found on a $15 \mathrm{~cm} \times 15 \mathrm{~cm}$ area after the examination of Garment B (scraping). Experiment 1 $0.5 \mathrm{~m}: \longrightarrow-1 \mathrm{~m}: \multimap-3 \mathrm{m:}-\Delta-$

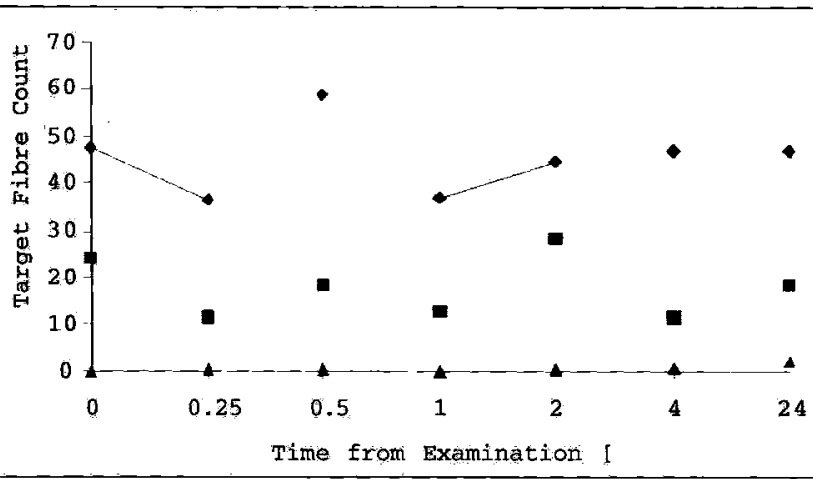

FIGURE 8 Number of fibres found on a $15 \mathrm{~cm} \times 15 \mathrm{~cm}$ area after the examination of Garment $C$ (taping). Experiment 1 $0.5 \mathrm{~m}: \longrightarrow-1 \mathrm{~m}: \rightarrow-3 \mathrm{~m}:-\Delta-$

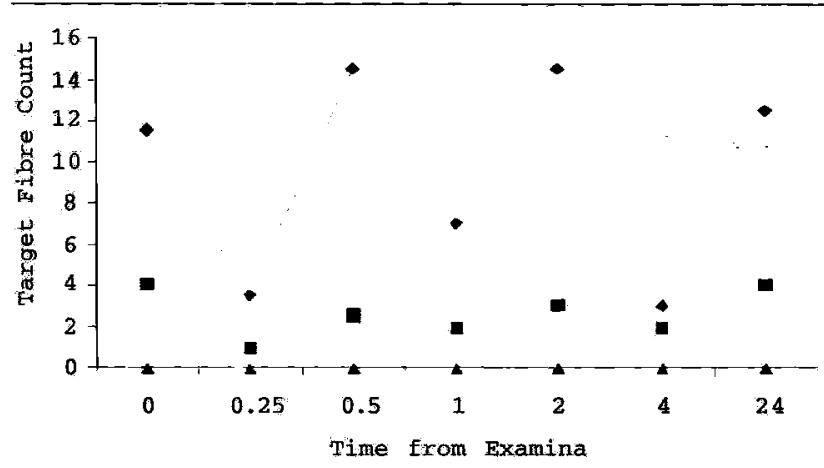

FIGURE 9 Number of fibres found on a $15 \mathrm{~cm} \times 15 \mathrm{~cm}$ area after the examination of Garment $D$ (taping). Experiment 1 $0.5 \mathrm{~m}:-1 \mathrm{m:} \rightarrow-3 \mathrm{m:}-\mathrm{A}-$

method. However, target fibres from Garment A were observed to still be present within the room up to 24 hours after the garment had been scraped. In general, the numbers of fibres found during the examination were significantly larger (more than threefold) when scraping was used rather than taping. Garment B, with a lower shed potential, produced only a slightly increased number of fibres with scraping compared to taping.

Experiment 3: Fibre movement out of the search room None of the adhesives left exposed for four weeks out of the 

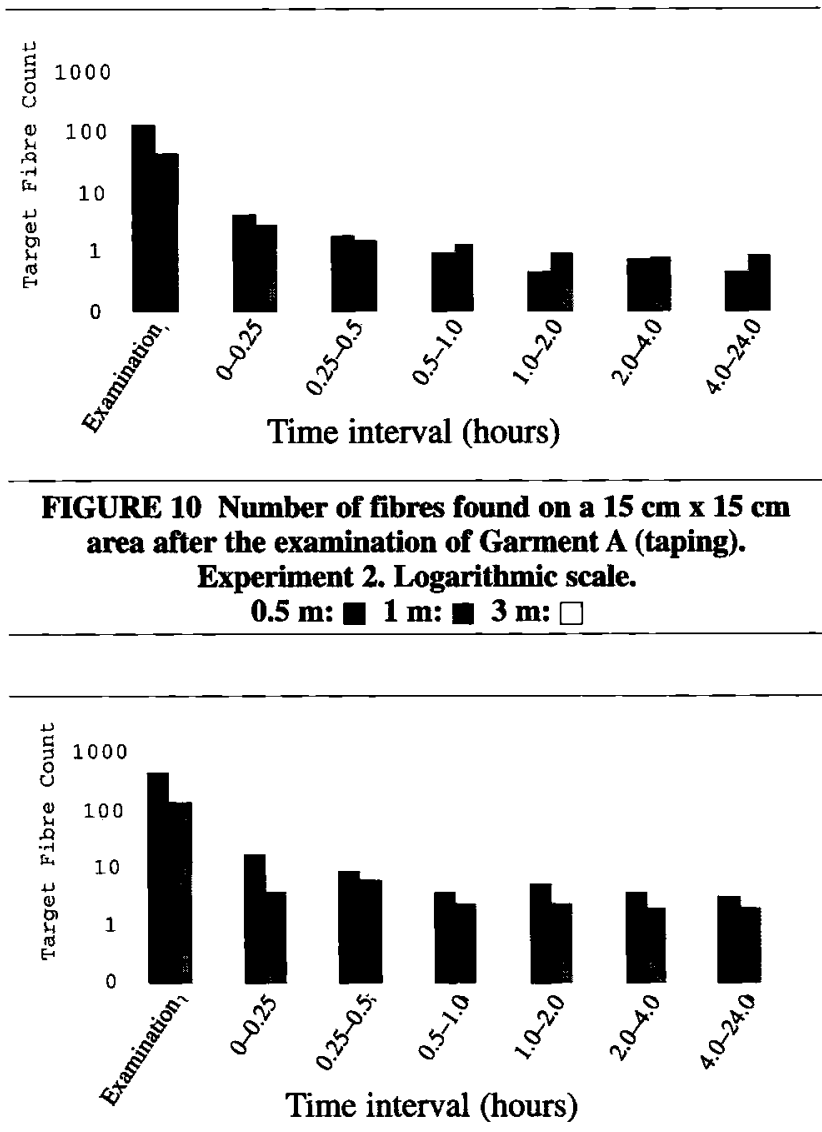

FIGURE 11 Number of fibres found on a $15 \mathrm{~cm} \times 15 \mathrm{~cm}$ area after the examination of Garment A (scraping) Experiment 2. Logarithmic scale. $0.5 \mathrm{~m}$ : $1 \mathrm{~m}: \mathrm{m}$ : $\square$

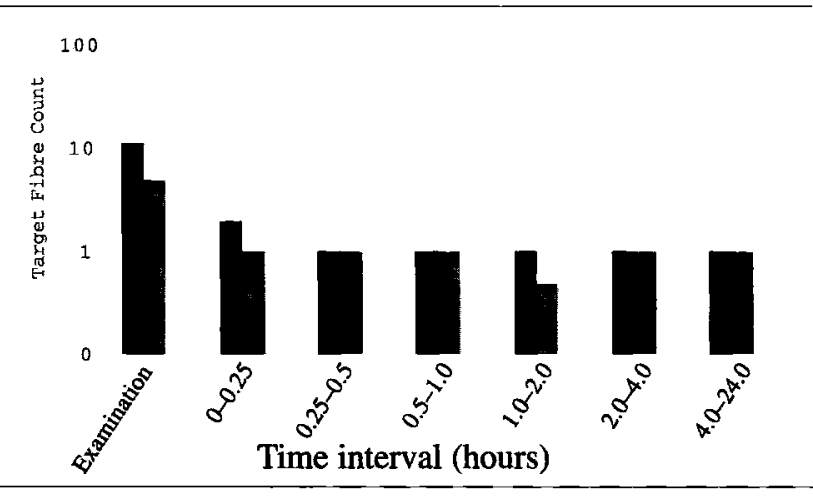

FIGURE 12 Number of fibres found on $15 \mathrm{~cm} \times 15 \mathrm{~cm}$ area after the examination of Garment $B$ (taping).

Experiment 2. Logarithmic scale. $0.5 \mathrm{~m}$ : $1 \mathrm{m:} 3 \mathrm{~m}$ :

search room collected any target fibres. Hence, no fibre movement was observed out of the search room within the four-week period after the mock examination.

\section{Experiment 4: Hygiene in the search room}

The first aim of this experiment was to see if the method used to clean the search room could create a greater potential for contamination. The data obtained did not show an increase in fibres settling over one or 24-hour periods after

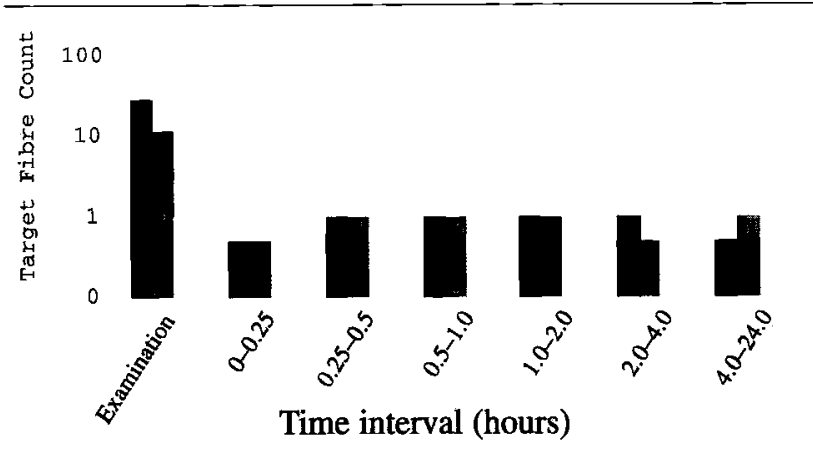

FIGURE 13 Number of fibres found on a $15 \mathrm{~cm} \times 15 \mathrm{~cm}$ area after the examination of Garment B (scraping).

Experiment 2. Logarithmic scale. $0.5 \mathrm{~m}: 11 \mathrm{~m}: \square 3 \mathrm{~m}:$

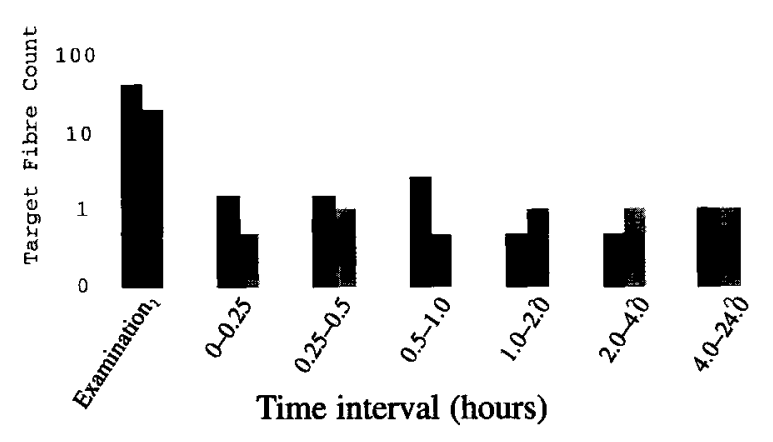

FIGURE 14 Number of fibres found on a $15 \mathrm{~cm} \times 15 \mathrm{~cm}$ area after the examination of Garment $\mathbf{C}$ (taping). Experiment 2. Logarithmic scale. $0.5 \mathrm{~m}: \square 1 \mathrm{~m}: \square 3 \mathrm{~m}: \square$

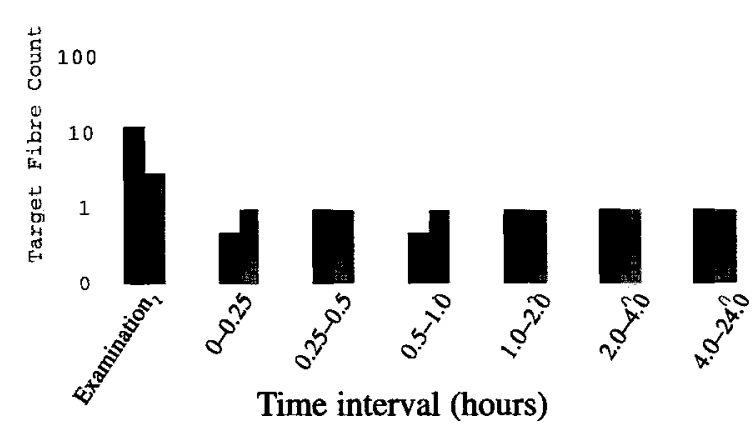

FIGURE 15 Number of fibres found on a $15 \mathrm{~cm} \times 15 \mathrm{~cm}$ area after the examination of Garment $D$ (taping). Experiment 2. Logarithmic scale. $0.5 \mathrm{~m}: \square 1 \mathrm{~m}: \square 3 \mathrm{~m}: \square$

sweeping, when compared to mopping the floor or no cleaning at all. Hence whether such cleaning steps include mopping or sweeping, this study found no major difference in terms of their ability to create airborne contamination (Table 2).

The second aim was to study the impact of the cleaning method on the actual search table. From the four methods used to clean the examination table, only dry paper towels 
were found to be less efficient, and even this difference was only small (Table 3 ). The use of paper as a table covering greatly increased the efficiency with which the bench could be cleaned, since once the paper was removed there were generally only few, if any, fibres remaining.

In the third trial, the collection of material onto protective clothing during an examination was examined (Figures 16-18).

With taping as the examination method, the examiner's front torso had on average 2.6 times more fibres when using standard laboratory coats compared to disposable suits. The laboratory coats also had the ability to retain on average $23 \%$ of the transferred fibres for at least one hour after the examination [the polypropylene suits were designed to be disposed of after an examination, and hence they were not tested for persistence] (Figure 16).

With Garment A, scraping transferred 9.3 times more target fibres to the examiner's clothing, when compared to taping. This difference was less significant when Garment B was used (Figure 17).

Carry-over fibres were defined in this study as those target fibres found deposited on tape-lifts from an experiment involving the garment from which the target fibre originated was not involved. Only three carry-over fibres (two from Garment A and one from Garment B) were found at a distance of $0.5 \mathrm{~m}$ following the taping experiments. Depending on the experiment and the location of the sampling, scraping generated more than five times the number of carryover fibres when compared to taping (Figure 18).

TABLE 2 Effect of different floor cleaning methods; target fibres = garment A

\begin{tabular}{|c|c|c|c|c|}
\hline Cleaning Technique & $\begin{array}{c}\text { Target Fibres Collected } \\
\text { over } 1 \mathrm{~h} \\
\text { Sample } 1\end{array}$ & $\begin{array}{c}\text { Target Fibres Collected } \\
\text { over } 1 \mathrm{~h} \\
\text { Sample } 2\end{array}$ & $\begin{array}{c}\text { Target Fibres Collected } \\
\text { over } 24 h \\
\text { Sample } 1\end{array}$ & $\begin{array}{c}\text { Target Fibres Collected } \\
\text { over } 24 h \\
\text { Sample } 2\end{array}$ \\
\hline Best Practice: Mopping & 1 & 1 & 2 & 2 \\
\hline $\begin{array}{l}\text { Average Practice: Neithe } \\
\text { Mopping or Sweeping }\end{array}$ & er & 0 & 3 & 2 \\
\hline Worst Practice: Sweeping & 0 & 4 & 2 & 3 \\
\hline
\end{tabular}

TABLE 3 Effect of different bench cleaning methods; target fibres = garment $A$

\begin{tabular}{|c|c|c|c|}
\hline Cleaning Technique & $\begin{array}{l}\text { Target Fibre Count } \\
\text { Before Wiping }\end{array}$ & $\begin{array}{c}\text { Target Fibre Count } \\
\text { After Wiping } \\
\text { Sample } 1\end{array}$ & $\begin{array}{c}\text { Target Fibre Count } \\
\text { After Wiping } \\
\text { Sample } 2\end{array}$ \\
\hline Dry paper towel & $27(100 \%)$ & $5(19 \%)$ & $7(26 \%)$ \\
\hline Paper towel and $70 \%$ ethanol & $27(100 \%)$ & $1(4 \%)$ & $2(7 \%)$ \\
\hline Dry non-shedding cloth & $19(100 \%)$ & $2(11 \%)$ & $1(5 \%)$ \\
\hline Non-shedding cloth and $70 \%$ ethanol & $24(100 \%)$ & $0(0 \%)$ & $1(4 \%)$ \\
\hline
\end{tabular}

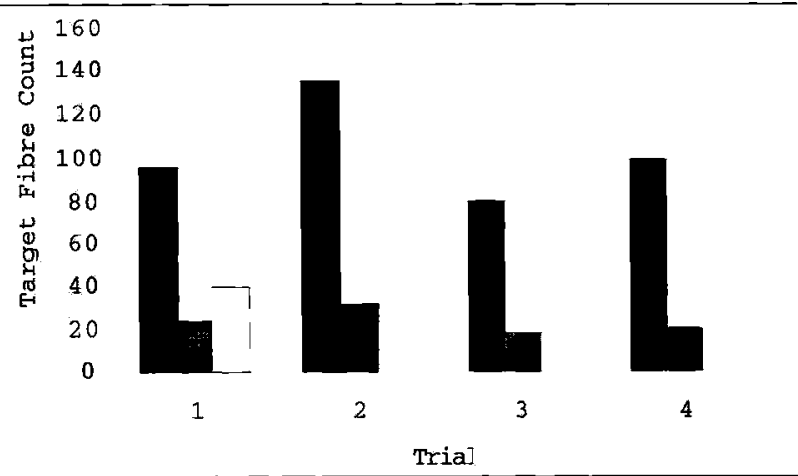

FIGURE 16 Number of fibres found after the examination of Garment A on a cotton labcoat v. polypropylene disposable suit.

Labcoat $t=0 \square$ Labcoat $t=60$ min: $\square$ Disposable $t=0: \square$

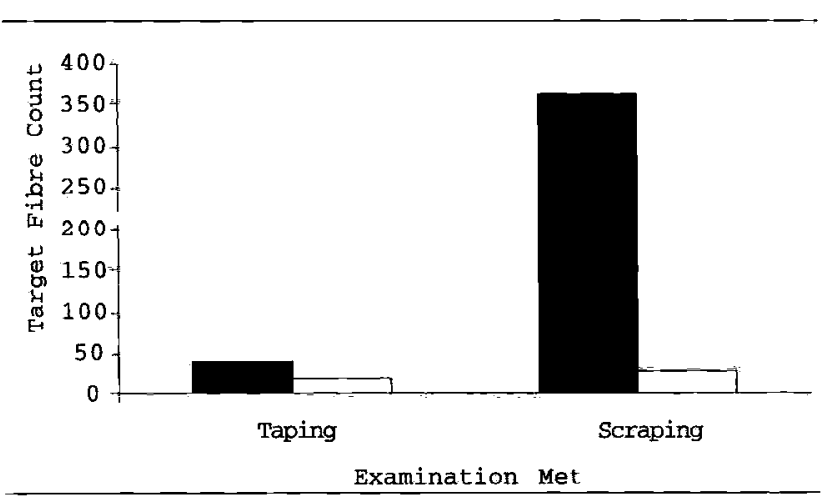

FIGURE 17 Number of fibres found after the examination of Garments $A$ and $B$ using the taping v. the scraping method. Garment A Garment B: 


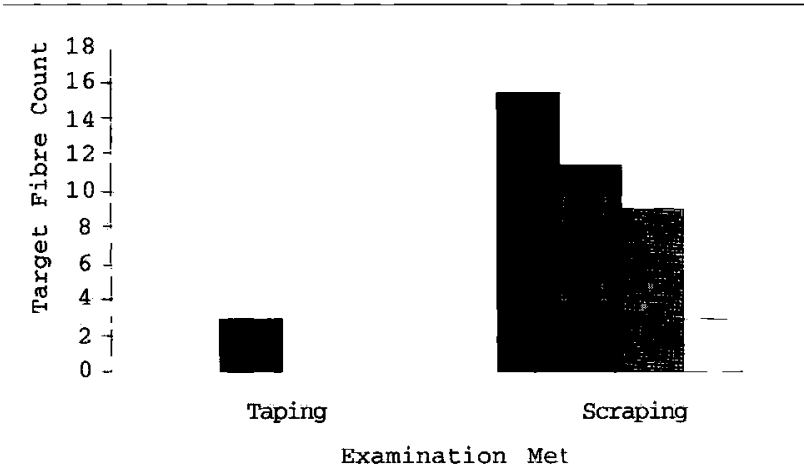

FIGURE 18 Number of carry-over fibres from one experiment to another using the taping $v$. the scraping method.

On the examiner: $\square 0.5 \mathrm{~m}: 1.0 \mathrm{~m}$ :

$3.0 \mathrm{~m}:$

\section{Discussion}

The limitation of any fibre transfer experiment lies in the difficulty in producing exactly the same absolute populations in repeat experiments. This is due to the numerous variables involved and the difficulty in controlling these variables. To minimise this problem in this study, experiments were repeated in a total of four search rooms, over a two year period. Similar orders of magnitude were obtained between repeated experiments. The authors are confident that the data presented in this paper allows valid generalisations and comparisons to be made.

Our results showed that fibre movement, and hence potential contamination, occurred when a garment was examined. In general, most fibres were deposited at short distances during the actual examination. That is, very few fibres were deposited at longer distances (e.g., $3 \mathrm{~m}$ ) or after the actual examination. However, the small numbers of target fibres found deposited on adhesives placed under the doorway to the search rooms showed that fibres could still move relatively long distances within the room. In no case were fibres found in other rooms distant from the examination room or in the corridor. This demonstrates a dilution effect of fibres into the general environment, and supports the assumption that the use of physically separated search rooms is a worthwhile practice in order to minimise the risk of contamination in fibre casework. However, it should be stressed that the examination rooms used were specifically designed for trace evidence processing with appropriate air pressure differentials and that the search protocols designed were designed to minimise contamination potential.

The extent of fibre contamination is mainly affected by the nature of the garment (i.e., its sheddability) and by the collection method. For example, it was observed in the experiments in which large numbers of cotton target fibres were produced that small numbers of fibres were still settling within the room, at the shorter distances ( $1 \mathrm{~m}$ and $0.5 \mathrm{~m}$ ), up to 24 hours after the examination. This agrees with the findings of Moore et al. [8] who reported that cotton fibres tended to stay airborne for much longer periods of time than wool fibres. The garments made of either acrylic, wool or polyester produced fewer loose fibres than the cotton garment. It was also observed that the movement of acrylic, wool and polyester fibres following examination of these garments was minimal compared to that of the cotton fibres from Garment A.

Our results also showed that, with the garments used in this study, scraping to recover fibre evidence produced more loose airborne fibres than taping. In most cases, between two and six times the number of fibres were found to have settled on corresponding adhesives. This seems to be a particular problem for the cotton garment (Garment A) which gave much higher numbers of airborne fibres when scraped, as compared to taped.

The fibres which remain within a search room after an examination are a very serious matter due to the possibility of those fibres transferring to other garments or evidential items during subsequent examinations. In this respect, the high number of potential contaminant fibres generated by scraping is primarily an issue in relation to cleaning. For example, in our scraping experiments, a number of orange cotton fibres (Garment A) were found to be still present in the room following cleaning and then further examination of another garment. In one experiment two separate cleaning steps using the best practice failed to remove the "residual" orange cotton fibres after Garment A was scraped. Hence, the cleaning practices administered in this study were ineffective in removing the large numbers of loose fibres produced by scraping Garment A. These results demonstrate that the application of effective hygiene practices is a significant issue for laboratories using scraping as a standard recovery method.

Similarly, the larger number of fibres produced by scraping resulted in a significantly larger number of fibres being transferred to the protective suit of the examiner, which in turn could be a potential source of contamination between garments.

Recovery techniques should aim to cause the minimum of disruption or displacement of fibrous materials [10]. In light of the results of this study, the authors cannot recommend scraping techniques for the collection of extraneous fibres from a fibrous surface.

Cleaning practices and hygiene in the search room play an important factor in preventing contamination problems, even when taping is used as the recovery method. Ideally, a search room should be as clean as possible from contaminant fibres, and therefore, the presence of material on the floor should be avoided. Whether such cleaning steps include mopping or sweeping, this study found no difference in terms of their ability to create airborne contamination. Wiping the examination table and the use of paper as 
a disposable table covering were also efficient to prevent contamination. However, the most important practice relates to the use of protective clothing during an examination. Our results showed that fibres were capable of sticking to standard laboratory coats in larger numbers than to polypropylene suits, and that approximately $20-25 \%$ of transferred fibres remained on the coat after one hour (Figure 16). For these reasons, disposable protective suits should be preferred to traditional laboratory coats. If this cannot be achieved because of the cost incurred, laboratory coats are acceptable. However, it is crucial to change into a clean laboratory coat before each examination, and to have different coats for different search rooms. Alternative protective suits, such as antistatic polyester coats, exist and are used in some laboratories. It would be worthwhile to test them in future contamination experiments. As Quality Assurance practice at the beginning of an examination, taping the bench and the front torso of the examiner would be beneficial in demonstrating that acceptable levels of cleanliness were obtained before performing the examination.

The search room design can also play some role in preventing fibrc contamination. For example, one of the features of the search rooms used in this study was the positive pressure air conditioning system designed to minimise the possibility of environmental contamination occurring within the search area. The purpose of the system is to move air currents out of the examination room and thus prevent air currents, and any fibres they carry with them, from entering the room and possibly contaminating an exhibit. It was apparent that fibres were being swept, by the air conditioning, across the room towards the doorway in most experiments. It can be argued that an uncontrolled movement of air into the search room equates to an uncontrolled movement of airborne fibres from the general environment, thus potentially creating fibre contamination, especially when there is no door or the door is continuously being opened and shut. Although a positive pressure air conditioning system seems preferable, more research needs to be conducted before one can reach a definitive conclusion in this respect.

\section{Conclusions}

This study has brought a wider perspective on the issues affecting potential fibre contamination in forensic search rooms. A number of conclusions can be made following the various experiments. Fibre movement was found to be dependent on distance, with fibre populations decreasing with increasing distance from the garment examination area. The movement of fibres seemed to mainly occur during the examination, with very limited deposition of material afterward.

With the specific garments used in this study and their respective sheddability, cotton fabrics generated the highest number of contaminant fibres, followed by wool, acrylic and polyester items. Cotton fibres were also found to be airborne for longer periods of time.

The scraping method of fibre recovery was found to result in an increase in fibre populations produced, fibres being transferred to the examiner's clothing and a number of fibres exiting the search room. In addition, the high number of fibres produced by scraping of the cotton garment resulted in residual contamination despite stringent cleaning practices. In comparison, taping produced lower fibre populations and hence lower contamination risk. Therefore, taping is a more acceptable method of fibre recovery, during garment examinations, when considering contamination issues.

Based on the results of this project it is unlikely that a completely clean search room can ever be obtained, even with best practice cleaning techniques. However, with proper precautions it is possible to minimise the contaminant fibre population, and the threat of truly problematic contamination. Best hygiene practice should include the use of two physically separate and dedicated search rooms, paper to cover the examination table, disposable protective suits, and monitoring the level of cleanliness by taping the bench and the front torso of the examiner before performing an examination. In any case, the presence of small numbers of particular fibres in search rooms means that extreme care should be taken when interpreting results involving only a few fibres. The use of large general examination rooms for trace evidence recovery cannot be recommended as there will clearly be a much greater chance for cross contamination. This is also the reason why it is risky to compare extraneous fibres from unknown sources found on two objects when trying to determine whether contact had occurred.

\section{Acknowledgments}

The authors would like to thank the staff of the Forensic Service - Australian Federal Police, Canberra, for their assistance during the experiments held in their laboratory. The members of the Criminalistics Specialist Advisory Group (SAG) of the Senior Managers of Australian and New Zealand Forensic Laboratories (SMANZFL) are also acknowledged for their participation in the survey conducted prior to this study. Mark Sandercock, Royal Mounted Canadian Police, Winnipeg, is also thanked for his suggestions during the preparation of the manuscript.

\section{References}

1. Roux, C, Langdon S, Waight D and Robertson J. The transfer and persistence of automotive carpet fibres on shoe soles. Science \& Justice 1999; 39(4): 239-251.

2. Gaudette BG. The forensic aspects of textile fibre examination. In: Saferstein R, ed. Forensic science handbook, Vol. 2. Englewood Cliffs: Prentice Hall, 1988: 209-272.

3. Grieve M. Fibres and their examination in forensic science. Forensic Science Progress 1990; 4: 41-125.

4. Siegel JA. Evidential value of textile fibre-transfer and persistence of fibres. Forensic Science Review 1997; 9: 81-96. 
5. Robertson J and Grieve M. Forensic Examination of Fibres. 2nd edition. London: Taylor \& Francis, 1999.

6. Grieve M. Back to the future -40 years of fibre examinations in forensic science. Science \&Justice 2000; 40(2): 93-99.

7. Kaufman F. The Commission on Proceedings Involving Guy Paul Morin. Ontario: Queen's Printer for Ontario, 1998: 1-407.

8. Moore JE, Jackson G and Firth M. Movement of Fibres between Working Areas as a Result of Routine Examination of Garments. Journal of the Forensic Science Society 1986; 26: 433-440.

9. Coxon A, Grieve M and Dunlop J. A Method of assessing the fibre shedding potential of fabrics. Journal of the Forensic Science Society 1992; 32: 151-158.

10. Robertson $\mathbf{J}$ and Roux C. Transfer, Persistence and Recovery of Fibres. In: Robertson J, and Grieve M, ed. Forensic Examination of Fibres. 2nd edition. London: Taylor \& Francis, 1999: 89-100. 